\title{
Designing Sustainable Humanitarian Supply Chains
}

\author{
Helen S.Y. Chen, Luk Van Wassenhove, T.C.E. Cheng
}

\begin{abstract}
This is a multidisciplinary study on operationalizing the UN Sustainable Development Goals (SDGs) in humanitarian operations through supply chain management methods. It is motivated by the belief that for SDGs to be pursued in humanitarian operations, they need to be contextualized in the idiosyncratic settings and approached systematically. Towards this end, this paper develops and operationalizes a strategic sustainable humanitarian supply chain framework using the design science approach. The study starts with analyzing the humanitarian operations characteristics and identifying the critical supply chain capabilities required for sustainable operations. It then re-conceptualizes sustainability in the humanitarian context and proposes a formula of sustainability performance in humanitarian operations. After that, the humanitarian supply chain structural components are delineated and decomposed into operational elements in order to identify the configurations that lead to optimal sustainability performance. The findings then converge into a framework to enable the identification of context-contingent sustainable supply chain strategies in humanitarian operations. This paper makes three contributions to SDG research: 1) it contextualizes sustainability in the humanitarian setting through postulating the concept and formula of net sustainability value as the single bottom line in humanitarian operations; 2) it increases operationality of SDGs in the humanitarian sector through the design of a strategic framework for sustainable humanitarian supply chains; and 3) it increases the interdisciplinarity of SDG research by using a generic supply chain framework that can be applied to integrate multilevel multidisciplinary sustainability studies.
\end{abstract}

Key words:

Sustainable development goals, sustainability, humanitarian operations, humanitarian supply chains 


\section{Designing Sustainable Humanitarian Supply Chains}

\section{Introduction}

- Motivation

Four European countries recently set all-time high temperature records in July 2019 (Climate Change Service, 2019). Climate change is accelerating and has incurred more frequent and severe natural disasters (ReliefWeb, 2019). Pursuing the United Nations Sustainable Development Goals (SDGs) indeed "are not optional, they are about survival" (Van Wassenhove, 2019). Humanitarian organizations (HOs) operate in often already vulnerable regions, so to them sustainability concerns are particularly pertinent (Pedraza-Martinez et al., 2011). Furthermore, HOs are also under pressure to improve cost-efficiency due to budget constraints (Besiou and Van Wassenhove, 2020) - for example, in 2018, more than $40 \%$ of their appeals for funding were unmet (OCHA, 2018). Yet, research on sustainable humanitarian operations is scarce and practitioners often find it hard to incorporate sustainability considerations into their daily operations.

Supply chain management offers a systematic approach to investigate the interface between sustainability and humanitarian operations (Starr and Van Wassenhove, 2014). It is also an area with a significant cost impact, given that more than $70 \%$ of funding is allocated to supply chain expenditures in disaster responses (HELP Logistics et al., 2018). However, current theories and methods in supply chain management are mostly built in the commercial context and cannot be directly applied to the humanitarian sector, as the latter differs significantly from the former (Van Wassenhove, 2006, Van Wassenhove and Pedraza Martinez, 2012). This study addresses the gap through the design of a strategic framework for sustainable humanitarian supply chains (HSCs).

\section{- Research Methods}

This paper builds upon knowledge and methods from multiple disciplines using the design science research (DSR) approach to develop a sustainable HSC strategy framework. The goal of the DSR strategy 
is to design and implement generic processes or systems aimed at solving practical problems (Van Aken, 2004, Van Aken et al., 2016). DSR in operations management can be regarded as a "management engineering" approach that involves adapting existing theories and/or methods in innovative ways to design generalizable solutions for practical problems (Corbett and Van Wassenhove, 1993, Van Aken et al., 2016). The practice-based, solution-oriented, and theory-contributing characteristics distinguish DSR from "management science" (or natural science) and explanatory science (Corbett and Van Wassenhove, 1993, Holmström et al., 2009), making it a methodological fit for this study.

\section{- Research Framework}

The study adapts the strategy-structure-capabilities-performance (SSCP) framework (Chen et al., 2009) backwards to organize the design processes. The SSCP framework is a combination of the strategystructure-performance framework and the resource-based view (RBV): the strategy-structure-performance framework suggests that an organization needs to fit its strategy with its context and its structure with its strategy in order to achieve desirable performance (Miles, 1978); the RBV posits that an organization can generate competitiveness by developing valuable and inimitable resources (Barney, 1991). Built on both, the SSCP framework proposes that for an organization to perform well, it needs to develop capabilities based on its context-contingent strategy and structure (Chen et al., 2009). Figure 1 shows the study's research framework based on the SSCP framework.

This paper is organized as follows: Section 2 reviews the relevant literature. By "looking forward, reasoning backward", Section 3 analyzes the contexts of humanitarian operations and identifies contextcontingent supply chain capabilities. Section 4 re-conceptualizes sustainability in the humanitarian context and proposes a definition of sustainability performance for HSCs. In Section 5, the HSC structural components are decomposed into operational elements and the configurations that lead to optimal sustainability performance are identified. Finally, a framework for identifying context-contingent sustainable HSC strategies is proposed in Section 6. 


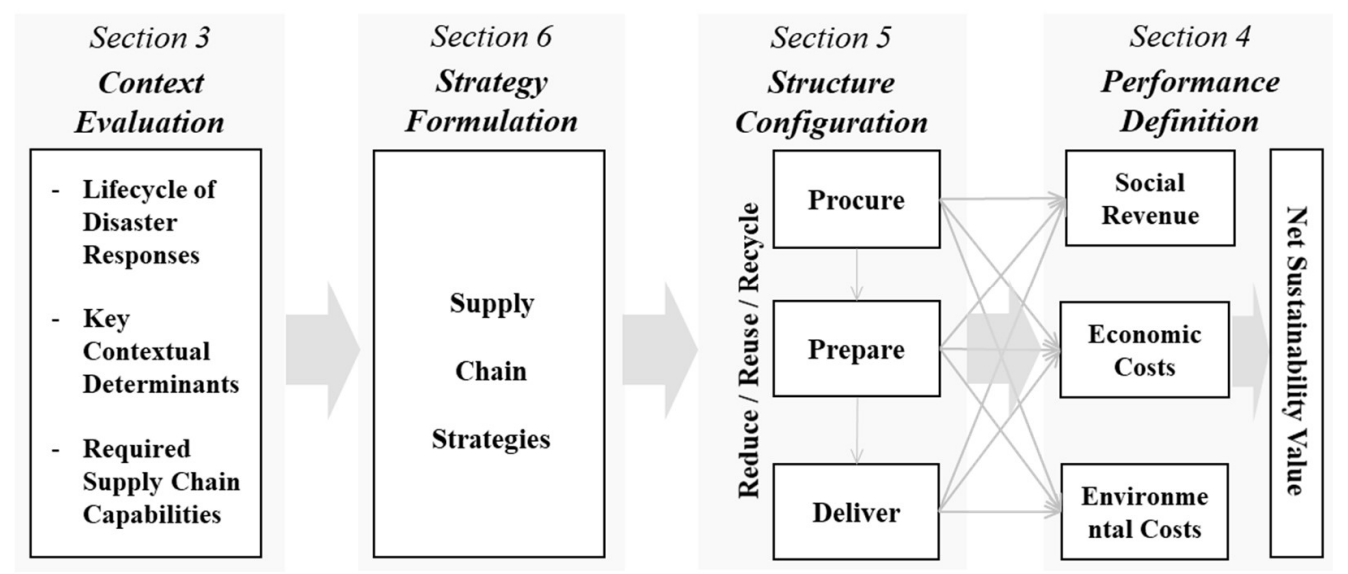

Figure 1 Research Framework

\section{Review}

\subsection{Humanitarian Operations}

Many HOs have dual missions of disaster responses and development programmes that involve both emergency and steady-state operations (Besiou et al., 2014). This can be referred to as a "service mix", similar to the concept of a "product mix" in business. Disaster responses are largely characterized by urgency, unpredictability, and complexity. Urgency and unpredictability are determined by the timing, type, location, scale, and severity of disasters. Complexity is the result of urgency and unpredictability compounded by different contextual and organizational factors. Given the challenges posed to supply chain design by disaster responses, discussions hereafter will primarily focus on this type of mission with development programmes left in the background.

\section{- Urgency}

High urgency is the dominating characteristic of most disaster relief missions, especially at the start of operations. Speed often becomes the overriding operational objective, particularly in the first 72 hours after a sudden-onset disaster in order to maximize life-saving opportunities for the affected regions (Tomasini and Van Wassenhove, 2009). Any delay in disaster responses could exponentially drive up the deprivation costs, which are the proxy economic value of human sufferings caused by a lack of access to basic life sustaining goods or services (Holguín-Veras et al., 2013). 


\section{- Unpredictability}

High unpredictability manifests in both the demand and the supply sides of HSCs. On the demand side, severity of damage and the scale of demand are for the most part unknown until the first post-disaster assessment is carried out (Balcik and Beamon, 2008). On the supply side, especially in situations like emergency disaster relief, many organizations and institutions are involved and effective coordination is often difficult (Acimovic and Goentzel, 2016), making it challenging for a single HO to assess the needs for and the potential effects of its own efforts within the collective actions.

Unpredictability may be reduced to a certain extent. For example, unpredictability in the occurrence and impact of disastrous events can be lowered through improved forecasting: natural disasters have their cycles, tropical cyclones can be forecasted with the overall number and intensity estimated, and disaster profiles of different regions can be outlined; predictability in post-disaster demand before on-ground assessment can be increased through expertise by estimating some of the basic essential items and the required quantities (Tomasini and Van Wassenhove, 2009). However, although improved predictability can be useful at the aggregate level (such as improving the overall preparedness and prepositioning of safety stocks globally), its usefulness during emergency responses in the short term is limited when forecast errors are not pooled geographically.

\section{- Complexities}

While urgency and unpredictability are generally mission-contingent, complexity is the result of urgency and unpredictability compounded by different contextual and organizational factors. First, HOs often operate around the globe with different types of missions. Unlike corporations that can cherry pick desirable markets, HOs do not have such a luxury: whenever missions call, they have to be present anywhere in the world, especially at places where others would like to avoid - scattered and difficult to reach last-mile distribution points experiencing turmoil and conflicts, underdeveloped infrastructure, and even governed by uncooperative regimes or controlled by threating militaries. Furthermore, problems encountered in different crises can be very different from one another (Starr and Van Wassenhove, 2014). 
Requirements for responses to pandemics (such as Ebola) are different from earthquakes (such as the Sulawesi response) or long-term conflicts (such as the Syria crisis). The level of complexity in establishing and managing new HSCs responding to different crises in these destinations should not be underestimated (Van Wassenhove, 2019).

Second, from a sustainability perspective, humanitarian operations need to consider and balance divergent values of different stakeholder groups. The key stakeholder groups include donors, beneficiaries, and nature, the silent and often neglected ultimate stakeholder. Without considering the possible existence of a geopolitical agenda (which is beyond the scope of this study), donors value economic efficiency without compromising the fundamental objectives to save lives, ease pain, and improve life quality (Pedraza-Martinez and Van Wassenhove, 2016, Kretschmer et al., 2014). Beneficiaries value speed and supply sufficiency in disaster responses: at the emergency relief stage, beneficiaries' suffering can increase non-linearly with time passing by without essential life-sustaining items (Holguín-Veras et al., 2013) and unmet demand could literally mean the difference between life and death (Tomasini and Van Wassenhove, 2009); in rebuild and development situations, beneficiaries value resilience, self-reliance, and long-term prosperity ("Building Back Better") (Starr and Van Wassenhove, 2014). Nature values sustainable consumption of renewable resources (depletion rate not exceeding replenishment rate), minimal consumption of non-renewable resources (low material/energy/water intensity of operations), and minimal negative environmental impacts from pollution and waste generation. These values only partially overlap and exert driving forces toward different directions.

Third, some organizational characteristics of HOs can complicate humanitarian operations. Unlike commercial corporations, HOs do not have a clear profit-seeking agenda or a command-and-control structure. As a result, bureaucracy may impose excessive controls and slow down the operations (Tomasini and Van Wassenhove, 2009). Furthermore, personnel turnover is often high, making organizational learning and knowledge cumulation ineffective (Van Wassenhove and Pedraza Martinez, 2012).

In sum, high levels of urgency, unpredictability, and complexities make humanitarian operations remarkably challenging. These characteristics affect HSCs in all its components and make sustainability 
considerations different in the humanitarian setting. Management theories and models developed for the commercial sector need to be adapted before they can be applied to the humanitarian context.

\subsection{Sustainable Humanitarian Operations}

Sustainable development is defined as "development that meets the needs of the present without compromising the ability of future generations to meet their own needs (The Brundtland Report, 1987, p. 43)". Built on Van Wassenhove (2006), we define sustainable humanitarian operations as humanitarian operations that reduce the vulnerability of certain populations by fulfilling their immediate needs and supporting them in building resilience and creating long-term prosperity prospects with minimum possible economic and environmental resources.

As succinctly put, SDGs “are not optional, they are about survival” (Van Wassenhove, 2019). Yet, practitioners often find it difficult to incorporate sustainability considerations into their daily operations, and research in sustainable humanitarian operations is still a nascent area of study.

\section{- Economic Sustainability}

It is commonly accepted that in disaster responses, concerns of economic sustainability are subordinate to easing human pain and saving lives (Gralla et al., 2014, Haavisto and Kovács, 2019). Such perspective is rarely challenged, probably due to its moral backing in the "Rule of Rescue" which argues that society has a moral obligation to rescue individuals facing avoidable peril, even if doing so implies high economic costs or inefficiencies (Jonsen, 1986).

Although few would argue against applying the "Rule of Rescue" when resources are abundant, it is of little guidance when resources are scarce (Holguín-Veras et al., 2013) which is often the case when taking into account the geographical scope and the temporal dimension of humanitarian missions. In such resource-constrained situations, the neglect of economic sustainability in some areas (or at the early stage) of disaster responses can negatively impact the resource availability for other areas (or at a later stage of humanitarian operations), incurring cross-regional (or inter-temporal) social inequality. This implies that 
the design of sustainable HSCs needs to adopt a global view and a broad horizon with a timeframe beyond emergency relief in disaster responses. As such, applications of the "Rule of Rescue" are likely to be limited.

\section{- Environmental Sustainability}

While focusing on alleviating suffering and improving life quality of the vulnerable, humanitarian operations also generate significant environmental impacts due to the materials they bring in, the consumption of natural resources, and the waste and pollutions generated (Pedraza-Martinez et al., 2011). In particular, disaster relief operations take place in vulnerable areas and the negative environmental effects caused to them could have impacts more severe than other well-functioning regions. Neglecting these impacts can lead to a vicious cycle between disasters, increased vulnerability of the affected regions, and intensified damage afterwards (Sodhi, 2016).

However, the environmental dimension is often ignored in humanitarian operations literature. Research on this topic is scarce (Sarkis, 2012) with only a few exceptions studying the effects of material convergence (Holguín-Veras et al., 2012) and discussing the limited practices in greening the livelihoods of beneficiaries (Haavisto and Kovács, 2014). Choices of green products and practices are rarely studied, with considerations of transportation emissions just recently starting to emerge. In grey literature, some examples of environmentally unsustainable operations were documented. For example, excessive use and disposal of non-biodegradable packaging materials such as plastic water bottles which could have been largely replaced by water filters and purifying tablets (Humanitarian Research Group, 2011). It is evident that there is limited consideration of environmental sustainability in humanitarian operations, in both practices and research.

\subsection{Sustainable Humanitarian Supply Chain Strategies}

Scholars have long advised taking a supply chain perspective as a key first step to investigate the intersection between sustainable development and operations management (Kleindorfer et al., 2005). Practitioners have also recognized the critical role of supply chain management in delivering goods and services to beneficiaries (Besiou and Van Wassenhove, 2020). A supply chain perspective offers a 
"systematic point of view" of all relevant factors in humanitarian operations as the basis of solid analyses to replace well-intended intuition (Starr and Van Wassenhove, 2014). A systematic approach with a holistic view makes visible the limitations of partial solutions that displace, rather than resolve, sustainability issues. As a result, silo effects and tunnel vision can be exposed, high leveraging points and key synergetic areas pinpointed, and optimal configurations in consonance with the benefits of the whole system can be identified. Therefore, supply chain management can serve as an anchoring point to integrate sustainability concerns in humanitarian operations. Built upon the definition of sustainable humanitarian operations in Section 2.2, we propose the following definition for sustainable HSC management:

Sustainable HSC management is a systematic approach to designing, organizing, and managing key intra- and inter-organizational processes in order to reduce the vulnerability of certain populations by fulfilling their immediate needs and supporting them in building resilience and creating long-term prosperity prospects with minimum possible economic and environmental resources.

Supply chain strategy is a critical starting point for sustainable HSC management since it deals with decisions that have long-lasting effects on an organization (Simchi-Levi et al., 2004). Research on supply chain strategies is rich. Fisher (1997) proposed a framework for choosing the right supply chain strategies based on product types ("efficient" for "functional" versus "responsive" for "innovative"). Lee (2002) further developed the framework into a $2 \times 2$ matrix for aligning supply chain strategies ("efficient", "responsive", "risk-hedging", and "agile") with uncertainties in demand and supply. Christopher and Towill (2001) recommended integrating lean and agile hybrid supply chain strategies in different contexts. SimchiLevi et al. (2014) advised managing unpredictable supply chain disruptions through identifying and mitigating low-probability, high-impact risks.

Despite the enlightening insights offered by these studies, they all focused on commercial supply chains. The supply chain strategies they proposed based on product and profit related characteristics are not directly applicable to the humanitarian context: HOs do not make products or chase profits, and they compete with rivalries in different ways. Furthermore, organizing completely new supply chains for humanitarian responses right after a disaster is more than just a different application of existing theories 
since the context is very different from commercial operations (Van Wassenhove, 2019). Sustainable HSC strategies need to be designed based on the idiosyncratic characteristics in the humanitarian context.

\section{Context-Contingent Supply Chain Capabilities}

Humanitarian operations take place in highly complex situations. Within the broader contexts of technological advancements and sociocultural diversities, sustainable HSC strategies need to effectively address the dynamics contingent on humanitarian missions. Therefore, it is necessary to carefully characterize and categorize different types of mission contexts and develop context-specific supply chain solutions generally applicable to those types of situations (Van Wassenhove, 2019).

\subsection{Lifecycle of Disaster Responses}

Figure 2 shows the three stages of a typical, albeit simplified, lifecycle of humanitarian disaster responses: Emergency Relief, Sustaining Relief, and Recovery \& Rebuild (development missions are not discussed in detail here since they are mostly stable and present less challenges to supply chain solutions).

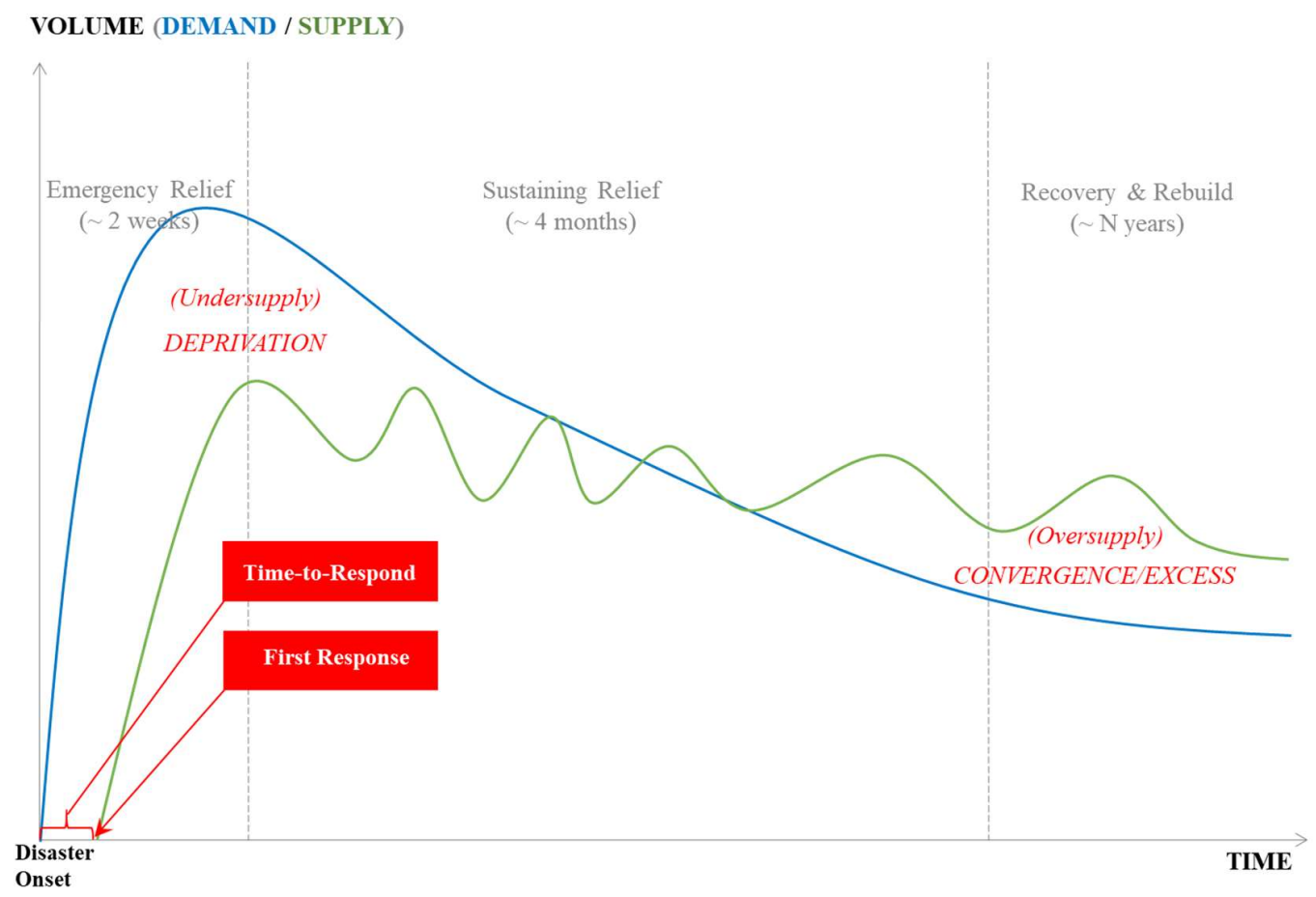

Figure 2 A Lifecycle View of Disaster Responses 
Upon the onset of a disaster, relief operations are triggered. Supplies are acquired from prepositioned stock, ad-hoc procurement, and in-kind donations. Depending on the distance between the locations of supply/demand and the mode of transport, the first supplies are delivered and distributed to beneficiaries ("First Response") after a certain period of time ("Time-to-Respond"). This is the most critical time for relief operations, since local supplies will soon drain out and unmet demands spike following a disaster before international aid comes in. This stage of disaster response may take roughly two weeks on average (Besiou et al., 2014) and is referred to as the Emergency Relief stage in this study. After the Emergency Relief stage, supplies from different sources gradually arrive and unmet demands gradually decrease. There will be fluctuations due to the volatility in the environment, but in general, the situation slowly calms down after the initial shock and the level of urgency continues to reduce. Local capacities may be partially recovering and refunctioning at this stage, easing the demand on international aid. This stage may take approximately four months on average (Besiou et al., 2014) and is referred to as the Sustaining Relief stage. After that, disaster responses gradually transition into new steady-state development stage for Recovery \& Rebuild, which may take up to several years. This is the transition from "response" to "rehabilitation" in the disaster management cycle (Tomasini and Van Wassenhove, 2009).

\section{- Sustainability Implications}

Figure 2 also illustrates the sustainability implications of mismatched supply and demand in disaster responses. For large-scale disasters causing damages beyond local coping capacity, there is typically undersupply at the Emergency Relief stage. The severity of the impacts caused by undersupply are determined by the length of Time-to-Respond and the volume/suitability of the relief items supplied. Any significant delay or insufficiency of suitable supply at this stage could exponentially drive up deprivation costs in human suffering and life losses. Deprivation cost can be considered missed opportunities to gain social revenue from easing suffering and saving lives through effective disaster responses, hence it is a type of opportunity cost on the social dimension of sustainability. 
Conversely, for high-profile disasters, international aid may exceed local demand at some point in the Sustaining Relief or Recovery \& Rebuild stages due to media attention and/or lack of effective planning of and coordination among the involved organizations. Temporary oversupply (or over-speed of supply) can cause material convergence which may delay the delivery of critical items and increase deprivation. Permanent oversupply (or over-sufficiency of supply), including unused mismatched supply from in-kind donation, becomes excesses/waste with unnecessary economic and environmental costs.

In sum, effective supply chain management has significant implications for sustainability in humanitarian operations and solutions developed need to consider the response lifecycle dynamics.

\subsection{Critical Success Factors and Key Contextual Determinants}

The above analysis on the dynamics in disaster responses surfaces two critical success factors (CSFs) for sustainability in HSCs: supply speed and supply sufficiency. In strategy management literature, CSF is defined as the crucial aspect that a strategy needs to address effectively in order to achieve its objective (Boynton and Zmud, 1984). Supply speed is determined by readiness for urgency, and supply sufficiency is determined by readiness for unpredictability - in other words, urgency and unpredictability in the context dictate supply speed and supply sufficiency. Supply speed and supply sufficiency together determine the availability of supply in disaster responses, i.e., the condition of having adequate suitable relief items at time of need.

Accordingly, to reason backwards, sustainability impacts of disaster responses are mainly the result of under-availability or over-availability, which are determined by supply speed and supply sufficiency, which are in turn determined by contextual urgency and contextual unpredictability. Therefore, the design of sustainable HSC strategies needs to focus on urgency and unpredictability, the two key contextual determinants of sustainability impacts in disaster responses.

Urgency is the emergency level of the need for humanitarian intervention, which is dictated by the scale and severity of the disaster and the functionality of local life-support systems. Unpredictability is determined by the timing of disaster onset and the organization's planning horizon: if supplies have been 
planned for during previous planning cycles, a sudden outbreak of a crisis can be considered "predictable" since there is preparedness for readiness in terms of supply sufficiency. Therefore, urgency is relatively absolute, but unpredictability is absolutely relative. Urgency is beyond an HO's control, but unpredictability is partly within its scope of influence. Since urgency determines the required supply speed and unpredictability the available supply sufficiency, speed is harder to manage in disaster responses than sufficiency. This can probably explain why that "it is easy to find resources to respond, it is hard to find resources to be ready to respond" (Tomasini and Van Wassenhove, 2009).

\subsection{Context-Contingent Supply Chain Capabilities}

To address urgency and unpredictability, general supply chain responses include expediting transportation, increasing safety stock, or reallocating resources. However, these responses are sub-optimal from a sustainability perspective, since they trade off cost-efficiency for speed and sufficiency. Sustainable supply chain responses require different approaches, for example, by adding alternative supply sources without pre-acquiring additional physical resources. Such responses demand different supply chain capabilities.

Supply chain capability as a concept is similar to manufacturing capability or competitive priority in operations strategy literature (Skinner, 1974, Hayes and Pisano, 1996, Ferdows and De Meyer, 1990). Operations strategy is the pattern of structural and infrastructural choices that guide decisions in operations to support overall firm objectives (Hayes and Pisano, 1996). Capability is the condition of having the capacity to do something. An organization needs to acquire adequate capabilities to enable the execution of its strategies in order to effectively address the CSFs and achieve its objectives.

The critical HSC capabilities include responsiveness, efficiency, reliability, flexibility, and agility (the "Critical Five"). Responsiveness is speed of response, i.e., the ability to configure and deploy resources to respond to mission calls quickly. Efficiency is leanness, i.e., the ability to achieve mission objectives with minimal waste in economic and environmental resources. Reliability is dependability, i.e., the ability to deliver goods/services in different situations as expected and with a predictable service level. Flexibility is 
versatility or adaptability, i.e., the ability to re-configure and redeploy resources to serve different missions. Agility is a higher-level composite capability, agility $=$ flexibility $x$ responsiveness: flexibility is the ability to adapt, responsiveness is the ability to act quickly, agility is the ability to adapt and respond to different missions quickly.

HSC capabilities required for sustainable operations are context-specific, contingent on the level of urgency and unpredictability of the situation. Furthermore, not all these capabilities are needed or attainable in all scenarios. Building on the trade-off theory (Fisher, 1997, Skinner, 1974) and the cumulative capability model (Ferdows and De Meyer, 1990, Noble, 1995), we propose the following 2x2 matrix (Figure 3) for the identification of context-contingent sustainable HSC capabilities:

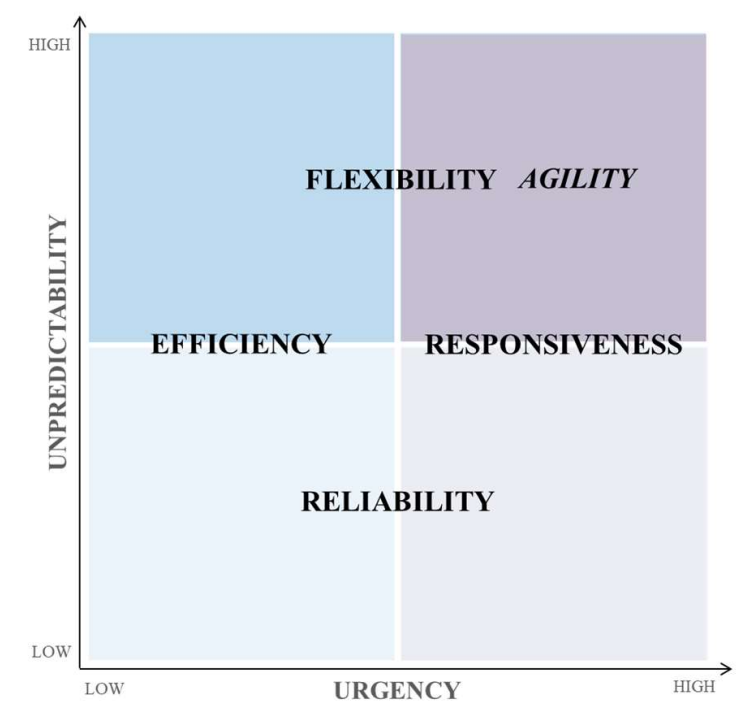

Figure 3 Context-Contingent Sustainable Supply Chain Capabilities

Urgency in the operating context determines the required supply speed. Highly urgent scenarios e.g., an earthquake or the sudden outbreak of civil war) require high response speed, demanding the capability of responsiveness to quickly activate and deploy resources to deliver emergency aid. Low urgency scenarios (e.g., the Recovery \& Rebuild stage of a disaster response) do not require fast responses, so focus can be shifted to cost-efficiency. There is a trade-off relation between efficiency and responsiveness. The quest for efficiency usually increases rigidity and decreases responsiveness: cost- 
efficiency is often achieved through standardization and scale of operations - both tend to make the processes more established and harder to change, resulting in a growing rigidity and consequently reducing supply chain responsiveness.

Unpredictability in the operating context affects supply sufficiency. The level of predictability is measured against the usual time horizon for disaster response planning and preparation. In scenarios with low unpredictability (e.g., long-term health care programmes), HOs have enough time to budget and procure the needed supplies in preparation for the humanitarian missions. Under such situations, the capabilities of efficiency and reliability are desirable. In unpredictable scenarios (such as transitioning from Emergency Relief to Sustaining Relief and Recovery stages), the capability of flexibility is required to acquire the needed supply without a lengthy planning and preparation time horizon. Flexibility and reliability are cumulative capabilities. Reliability is the required foundation for flexibility to be built upon, so that the service level would be dependable and not compromised during the dynamic transitions when the supply chain is adapted to serving unpredictable missions.

In sum, the analysis shows that urgency has stronger sustainability impact than unpredictability: the level of urgency dictates an "either/or" trade-off relation that something (certain dimensions of sustainability) has to be given up for something else (the other dimensions of sustainability); while the level of unpredictability dictates a "first-then" cumulative relation that something has to be built first before something else can be pursued. It also shows that to be able to serve dynamic missions with a sustainable approach, HOs need to develop a portfolio of supply chain capabilities. The next section re-conceptualizes sustainability in the context of HSCs.

\section{Re-conceptualizing Sustainability in Humanitarian Supply Chains}

As discussed previously, management theories and methods developed in the commercial sector are not directly applicable to humanitarian operations. Sustainability related studies are no exception. This section clarifies the concept of sustainability in the humanitarian setting, examines the interactions among its three dimensions, and evaluates the sustainability performance impact of contextual contingencies and supply chain capabilities. The purpose is to set clear performance goals for the design of sustainable HSCs. 


\subsection{Single Bottom Line vs. Triple Bottom Line}

Sustainability in the commercial setting is operationalized as a Triple Bottom Line incorporating economic, environmental, and social dimensions (Elkington, 1994). It is a succinct way to communicate the abstract concept of sustainability to practitioners using simple and relatable terms. However, there is no such a thing as Triple Bottom Line in the humanitarian sector - there is only one Single Bottom Line instead.

\section{- Triple Bottom Line in the Commercial Sector}

For profit-seeking corporations with sustainability concerns in the private sector, the three dimensions of sustainability take different positions in the formula leading to profitability. They are not heterogenous elements though: the economic profit/loss is the "end", while the environmental and social profits/losses are the "means" to the "end". Business performance can be measured as: total net revenue = (gross economic revenue - economic cost $)+($ gross environmental revenue - environmental cost $)+($ gross social revenue - social cost), as illustrated in Figure 4.

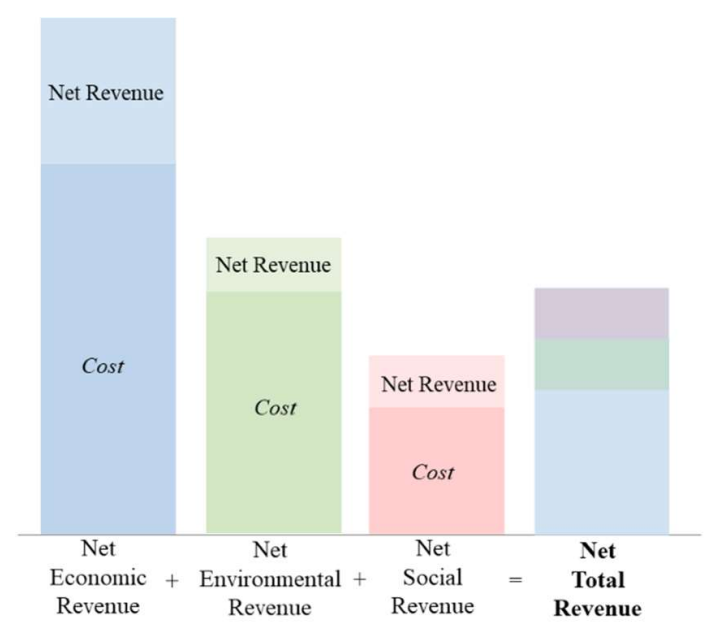

Figure 4 Triple Bottom Line of Sustainability in the Commercial Sector

This is a realistic, albeit simplified, definition of business performance involving sustainability: the key performance indicator, total net revenue, or profitability, is the result of traditional net economic profit/loss (private benefits) plus net environmental and social profits/losses from monetized environmental and social benefits (public benefits) minus internalized environmental and social costs (public costs). It is 
different from the broader conceptualization of sustainability performance in businesses with a normative perspective where externalities are considered but not practically internalized.

This simple illustration shows that if not mandated by legislations or demanded by powerful stakeholders (such as the boards, investors, customers) but left to managers' discretionary choices, rational decisions for profit maximization would be to only take sustainable actions when 1) there is a functioning "market for virtue" to materialize return on investments along the environmental/social dimensions; 2 ) the negative externalities are internalized as private costs (or environmental/social irresponsibility would lead to private economic gains); 3) a cost-benefit analysis suggests positive returns, i.e., there are positive net revenues on the environmental/social dimensions ("It pays to be green/good"). In short, sustainability needs to make business sense to rational managers for it to be practiced. The normative argument that managers have a social responsibility to sacrifice private gains for public good is likely to be effective only with the already socially conscious few.

\section{- Single Bottom Line in the Humanitarian Sector}

Humanitarianism per se is about "doing good". This means that humanitarian operations have a normative goal to create and deliver social value. Thus, the social revenue is the "end", while the economic and environmental costs invested to achieve the social goal are "means" to the "end". We define social revenue (SR) as the value generated from eased human suffering, saved lives, improved life qualities, and increased prosperity prospects of the vulnerable populations served through humanitarian interventions. There is a distinction between reducing suffering and improving life qualities - the former can be thought of as "reducing unsustainability", while the latter as "creating sustainability". It is the combined absolute value of both, with unsustainability reduced counted as sustainability gained, that comprises the total value of $\mathrm{SR}^{1}$.

\footnotetext{
${ }^{1}$ Equity (the "fairness, impartiality, or equality of service") is another key concern on aid delivery in humanitarian operations (McCoy and Lee, 2014). Equity, if measured, can be transformed into an index, $\alpha$, with its value ranges between 0 to 1 . Perfectly equal distribution of humanitarian aid is indexed at the value of 1 and unequal distributions are indexed according to the levels of equality. The value of SR is then adjusted as $\mathrm{SR}_{\alpha}$ to account for the level of equity in aid distribution. Since we are not able to go into more depth in the discussions about equity, SR instead of $\mathrm{SR}_{\alpha}$ will be used in this study, assuming it is the equity-adjusted value of SR.
} 
Borrowing terms from business accounting, on an HO's Sustainability Income Statement (or Sustainability Profit and Loss), SR created from "goodness done" is the top line, the economic costs $\left(\mathrm{EC}_{1}\right)$ and the environmental costs $\left(\mathrm{EC}_{2}\right)$ are the middle lines, and the Net Sustainability Value (NSV) left after deducting $\mathrm{EC}_{1}$ and $\mathrm{EC}_{2}$ from $\mathrm{SR}$ is the bottom line. Thus, sustainability performance in humanitarian operations can be measured as

$$
N S V=S R-E C_{1}-E C_{2} .
$$

From a sustainability perspective, NSV should to be the key performance indicator of humanitarian operations: $\mathrm{EC}_{1} / \mathrm{EC}_{2}$ (the middle lines) are input and process, but not result, performance indicators; while SR (the top line) is a partial result performance indicator measuring only "gross", but not "net", revenue. NSV is a composite latent measure: it is highly context-specific, hard to quantify, and does not have a common unit of measurement. Yet, it serves as a critical first step in conceptualizing and explicating the relationships among the key dimensions of sustainability performance in humanitarian operations.

Since there does not exist a traditional market to generate economic return on investment in $\mathrm{EC}_{1}$, nor a "market for virtue" to capitalize on investment in $\mathrm{EC}_{2}$, the Triple Bottom Line in businesses does not apply in the humanitarian sector. Instead, there is only one Single Bottom Line, NSV, in humanitarian operations, as shown in Figure 5:

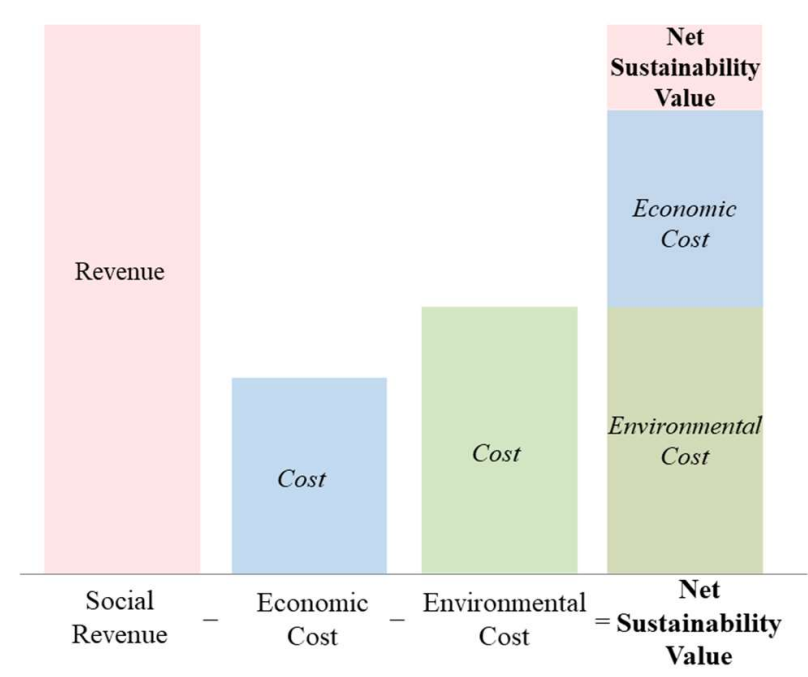

Figure 5 Net Sustainability Value, the Single Bottom Line in the Humanitarian Sector 


\section{- NSV as a Gentle Nudge Towards Sustainability}

The concept of NSV offers a holistic frame on the components of sustainability performance in humanitarian operations. NSV may become negative when the sum of $\mathrm{EC}_{1}$ and $\mathrm{EC}_{2}$ exceeds $\mathrm{SR}\left(\mathrm{EC}_{1}+\mathrm{EC}_{2}>\right.$ SR). In such case, although there is positive SR created ("gross revenue"), the ultimate performance of humanitarian operations ("net revenue") is against sustainability ("net loss"). This can serve as a gentle nudge for a slight paradigm shift in unsustainable disaster response practices guided by "Rule of Rescue". In emergency disaster response with sufficient funding, "firefighting” operations can easily become socialdominant, adopting as-much-as-possible as-soon-as-possible (“a-map-a-sap”) practices. This operation model is unsustainable since NSV may have a high negative value when the sum of $\mathrm{EC}_{1}$ and $\mathrm{EC}_{2}$ largely exceeds SR. A more sustainable approach would be to follow the as-much-as-necessary as-fast-asnecessary ("a-man-a-fan") rule, i.e., "just enough" (supply sufficiency) and "just in time” (supply speed) for supply to catch and match with demand. Such a rule can be operationalized through sustainable HSC design.

\subsection{Associations Among Three Sustainability Dimensions}

It was initially proposed that $\mathrm{NSV}=\mathrm{SR}-\mathrm{EC}_{1}-\mathrm{EC}_{2}$. This formula can be rearranged as $\left(\mathrm{EC}_{1}+\right.$ $\left.\mathrm{EC}_{2}\right)+\mathrm{NSV}=\mathrm{SR}$, i.e., SR created by humanitarian operations equals the sum of $\mathrm{EC}_{1} / \mathrm{EC}_{2}$ and $\mathrm{NSV}$. This shows that the three sustainability dimensions assume different roles and responsibilities in generating sustainability values. Therefore, differentiating the associations between the "cost components" $\left(\mathrm{EC}_{1}+\mathrm{EC}_{2}\right)$ and the "revenue component" (SR) from the interactions among the two "cost components" $\left(\mathrm{EC}_{1}\right.$ and $\left.\mathrm{EC}_{2}\right)$ is necessary.

Regarding the interactions between $\mathrm{EC}_{1} / \mathrm{EC}_{2}$ and $\mathrm{SR}$, using terms such as "trade-off" or "synergy" indiscriminately to describe the interactions among the trio may confuse rather than clarify, since both terms implicitly imply that the three dimensions are heterogenous elements constituting sustainability. Instead, "trade-off" seems to be about "prioritization" (e.g., buy speed with money) and "synergy" about "efficiency" (e.g., improved resource utilization for better service quality). As for the interactions between the two "cost 
components" $\left(\mathrm{EC}_{1}\right.$ and $\left.\mathrm{EC}_{2}\right)$, there appear to be more synergetic than trade-off opportunities. For example, supplies located close to beneficiaries cost less for transportation and incur lower negative environmental impacts; less packaging or better consolidation can reduce both packaging/transportation costs and environmental impacts; well-planned low frequency/big lot sizes are usually cheaper and greener than high frequency/small lot sizes; the modes of transport by sea/land are cheaper and greener than airlift; and the "Reduce, Reuse, Recycle" practices are generally beneficial both economically and environmentally. This suggests that the synergies between $\mathrm{EC}_{1}$ and $\mathrm{EC}_{2}$ might be a high leveraging area for NSV that can be harnessed through sustainable HSC design.

The above analysis surfaces the complex associations among the three dimensions of NSV. The sustainability performance measure of NSV therefore needs to be modified as

$$
N S V=f\left(S R, E C_{1}, E C_{2}\right) .
$$

The brief analysis also shows that the co-variations among the trio reflect the heterogenous effects on the three dimensions of lower level operational variables. Section 5 will systematically identify the operational variables along the end-to-end HSCs and examine their effects on the three sustainability dimensions to better understand these underlying multifaceted interactions.

\subsection{Contextual $\mathrm{U}^{2}$ and Supply Chain Capabilities}

Contextual urgency and unpredictability (U-Square, or $\mathrm{U}^{2}$ ) can negatively affect NSV if not properly addressed. When urgency is high and supply speed is crucial: 1) in the social-dominant scenario where "Rule of Rescue" is followed, in order to meet a pre-determined level of SR, the $\mathrm{EC}_{1 / 2 C_{2}}$ costs will be high (e.g., using chartered flights for delivery and helicopters for distribution); 2) in the economicconstrained scenario, since the available $\mathrm{EC}_{1}$ is capped by funding, the achievable level of SR will be lower since the speed and sufficiency of supply may be negatively affected. When unpredictability is high and the prepared supply is insufficient: 1) in the social-dominant scenario, the $\mathrm{EC}_{1} / \mathrm{EC}_{2}$ costs will be increased since alternative sources at higher costs or farther locations may need to be activated to meet the unpredicted demand increase; 2) in the economic-constrained scenario, the achievable level of SR will be lower since 
the volume of available alternative supply is capped by the available funding. Thus, the measure of NSV needs to be further modified as follows:

$$
N S V=f\left(U^{2},\left(S R, E C_{1}, E C_{2}\right)\right) .
$$

$\mathrm{U}^{2}$ along the lifecycle of a disaster response is not static: it is very high at the Emergency Relief stage, starts to decrease at the Sustaining Relief stage when the situation stabilizes, continues to fall as the mission transitions into Recovery \& Rebuild, and eventually plateaus when the mission becomes a yearlong development programme. Therefore, a portfolio of robust supply chain capabilities is needed to enable the fit between responses and contextual dynamics.

Supply chain capabilities (SCC) can counteract and neutralize the negative effect of $\mathrm{U}^{2}$ on NSV, serving as a substitute of $\mathrm{EC}_{1 /} \mathrm{EC}_{2}$ costs and a guardian for SR. The five critical HSC capabilities have been identified as Responsiveness, Efficiency, Reliability, Flexibility, and Agility. Responsiveness enables an HO to deliver at the speed required by the level of urgency; Flexibility allows adaptive approaches to acquire alternative supply sources in meeting unpredictable demands; Agility, or Flexible Responsiveness, enables adaptive and fast actions responding to both high urgency and high unpredictability. The formula of NSV thus need to be modified again as follows:

$$
N S V=f\left(S C C, U^{2},\left(S R, E C_{1}, E C_{2}\right)\right) .
$$

This qualitative formula does not attempt to precisely capture the computations of NSV in humanitarian operations. Rather, it intends to identify the relevant key factors affecting NSV with a holistic view and depict their relations roughly in order to guide the design of sustainable HSCs. Given that sustainability is a long-term systems issue and research in sustainability is still going through its burgeoning stage, a holistic perspective enabling the inclusion of all critical factors can offer more intellectual and practical value compared with precision in measuring an isolated portion of the relevant aspects. A holistic perspective can avoid tunnel vision and the resultant locally optimal but globally undesirable solutions that dispose of, rather than resolve, sustainability issues. 


\section{Sustainable Supply Chain Configurations}

Supply chain structure has far-reaching impact on sustainability performance since it encompasses the end-to-end processes of organizing, processing, and delivering humanitarian goods and services. This section decomposes supply chain structural components into operational elements, identifies alternative operational choices of each element, evaluates sustainability implications of each choice, delineates the structural configuration leading to optimal NSV, and finally, surfaces the emerging sustainable supply chain strategies.

This method is partly informed by lifecycle analysis in product design where product engineers assess the aggregated environmental impacts of alternative design blueprints with different parts and subassemblies in order to identify optimal product configurations. It is also guided by the design science approach in that 1) the identification of the processes and operational choices are grounded on the author's intensive field practices in global supply chain management, and 2) the evaluation of sustainability performance implications is built on relevant theories and models whenever appropriate and applicable.

\subsection{Structural Configurations and Sustainability Implications}

Built upon the generic supply chain framework (Chen et al., 2019), Figure 6 shows the key configurative components in HSCs. The structural components include Procure, Prepare, Deliver, Reduce/Reuse/Recycle $\left(\mathrm{R}^{3}\right)$, and the overarching supply chain strategies. The infrastructural components include physical assets, IT systems, and organizational missions and policies. In the upstream, the types of supply include prepositioned safety stock, ad-hoc procurement, and in-kind donation. In the downstream, the supply chain may serve directly the beneficiaries or via agents such as implementing partners. The subsection focuses on the structural components of Procure, Prepare, and Deliver. 


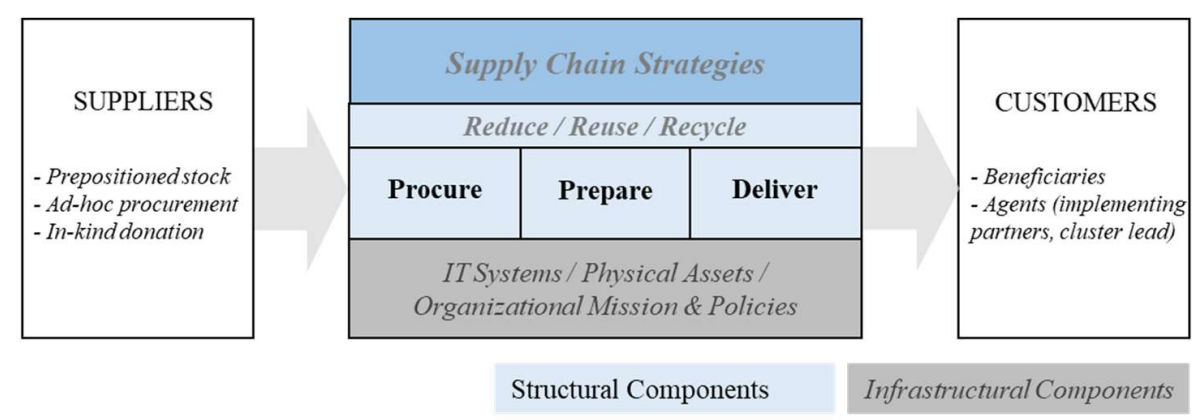

Figure 6 Humanitarian Supply Chain Structure

The $\mathrm{R}^{3}$ component in the supply chain configuration will not be analyzed individually, but its principles will be incorporated into the analysis and the design. The rationale is that HSCs usually do not involve product design, manufacturing, product take-back, and remanufacturing. Integrating the $\mathrm{R}^{3}$ principles into the structural configurations of process design is also consistent with the total quality management method that preventive mechanisms are preferred over corrective mechanisms. The $\mathrm{R}^{3}$ principles are contextualized in HSCs as follows and will be followed in the design whenever applicable: 1) Reduce: reduce material consumption/packaging by sharing and pooling, reduce energy consumption and pollution by shortening travel distance and using less energy-intensive transport modes, reduce nonvalue adding processes and activities; 2) Reuse: buy second-hand instead of new, rent instead of buy, increase material versatility for multi-purpose use; and 3) Recycle: repurpose of excess supply, recovery of residual value, and responsible waste disposal.

\section{- Sustainability Impact Evaluation}

Table 1 shows the comparison of different supply chain structural configurations and their NSV implications. The evaluation takes four steps: 1) first, the supply chain structural components are decomposed into key operational elements; 2) second, the dichotomous options for each operational element are identified (simplifying the range of potential options into dichotomous alternatives increases clarity of the process without compromising the validity of results); 3) third, the performance impact on three sustainability dimensions is compared between each pair of operational options; 4) fourth, the outperformed operational choices with higher pairwise NSV impacts are located and highlighted. Steps 1) 
and 2) are built on the author's intensive field experiences managing commercial and HSCs; Step 3) is guided by the $\mathrm{R}^{3}$ principles and the Circular Economy concepts such as "local circles" and dematerialization (Stahel, 1982); and Step 4) is carried out by simple counting and comparison. This evaluation process analyzes the global performance impacts of key operational options at the outset, exposes locally optimal myriad decisions, and surfaces overall sustainable supply chain configurations.

\begin{tabular}{|c|c|c|c|}
\hline \multirow{2}{*}{ STRUCTURAL COMPONENT } & \multicolumn{3}{|c|}{ SUSTAINABILITY IMPLICATION } \\
\hline & SR & $-\mathbf{E C}_{1}$ & $-\mathbf{E C}_{2}$ \\
\hline \multicolumn{4}{|l|}{ P1 PROCURE } \\
\hline \multicolumn{4}{|l|}{ P1.1 Location of Supply Source } \\
\hline - Local & + & + & + \\
\hline - Global & - & - & - \\
\hline \multicolumn{4}{|l|}{ P1.2_No. of Supply Sources } \\
\hline - Single & - & - & $=$ \\
\hline - Multiple & + & + & $=$ \\
\hline \multicolumn{4}{|l|}{ P1.3 Type of Supply } \\
\hline - Generic Products & $=$ & $=$ & - \\
\hline - Green Products & $=$ & $=$ & + \\
\hline \multicolumn{4}{|l|}{ P1.4_Timing of Procurement } \\
\hline - Prepositioned Procurement & + & - & - \\
\hline - Postponed Procurement & - & + & + \\
\hline \multicolumn{4}{|l|}{ P2 PREPARE } \\
\hline \multicolumn{4}{|l|}{ P2.1_Level of Inventory } \\
\hline - Low & - & + & + \\
\hline - High & + & - & - \\
\hline \multicolumn{4}{|l|}{ P2.2_Management of Inventory } \\
\hline - Self-Managed & + & - & - \\
\hline - Vendor-Managed & - & + & + \\
\hline \multicolumn{4}{|l|}{ P2.3_Level of Processing } \\
\hline - Low & - & + & + \\
\hline - High & + & - & - \\
\hline \multicolumn{4}{|l|}{ P2.4_Location of Inventory } \\
\hline - Local & + & + & + \\
\hline - Global & - & - & - \\
\hline \multicolumn{4}{|l|}{ D3_DELIVER } \\
\hline \multicolumn{4}{|l|}{ D3.1 Mode of Transport } \\
\hline- Air & + & - & - \\
\hline - Land/Ocean & - & + & + \\
\hline
\end{tabular}

Table 1 Supply Chain Structural Configuration \& Sustainability Performance Implications

Within the Procure (P1) component, key operational elements include Location of Supply Source (P1.1), No. of Supply Sources (P1.2), Type of Supply (P1.3), and Timing of Procurement (P1.4). The 
alternative options in P1.1 are Local and Global. Compared with Global, the Local option has higher positive performance impacts on all three dimensions of SR (faster delivery and developing the local economy), $\mathrm{EC}_{1}$ (lower transportation costs), and $\mathrm{EC}_{2}$ (lower fuel consumption). Therefore, a plus sign, “+”, is assigned to each cell on the row of Local and this option is highlighted in red as it outperforms Global overall. The minus sign "-_" before $\mathrm{EC}_{1}$ and $\mathrm{EC}_{2}$ (“- $\mathrm{EC}_{1}$ " and "- $\mathrm{EC}_{2}$ ") on the header shows the desirable direction of the impact, so that the effects of the operational decisions on all three dimensions are in a consistent direction.

The alternative options in No. of Supply Sources (P1.2) are Single or Multiple. There are three types of HSC supplies (prepositioned stock, ad-hoc procurement, and in-kind donation, as shown in Figure 7). Multiple sources outperform Single source on the SR dimension, since sufficiency and speed of supply are more likely to be ensured through multiple supply sources. Multiple sources may also outperform on $\mathrm{EC}_{1}$, considering the potential economy of scale and the possibility to elicit in-kind donations without incurring buying costs. However, it is uncertain with $\mathrm{EC}_{2}$, as indicated by neutral " $=$ " sign: Single source of prepositioned stock and ad-hoc procurement can reduce transportation costs and environmental impacts; Multiple sources with in-kind donations may Reuse and Recycle second-hand items or repurposed overstocks, but such in-kind donations may not meet the beneficiary needs and become wasteful. Overall, Multiple still outperforms Single source in its sustainability implications and is therefore highlighted.

The rest of the comparisons are self-explanatory and will not be discussed in length here. In summary, the evaluation shows that sustainable HSCs are configured with operational elements, including 1) local and multiple sources of supply, green products, postponed procurement; 2) low levels of inventory managed by vendors and low levels of processing; and 3) delivered by ocean/land.

This exercise is valuable primarily because it forces and reinforces systems thinking. It demands the evaluator to think through the implications of the options on different aspects before jumping at premature conclusions on locally optimal solutions that might be globally sub-optimal. It also requires that the evaluation covers comprehensive and mutually exclusive operational elements to avoid overlooking or overlapping of key steps. Systems thinking is crucial in sustainability research since it can facilitate 
considerations of both short- and long-term, proximate and distant, beneficial and harmful effects of certain operational choices (Sterman, 2000). As a result, it can enrich our understanding of the dynamics in HSCs and enable better informed decision analysis. For example, the evaluation shows that Prepositioned Procurement is likely to be a sub-optimal choice from a sustainability perspective, since it is a type of tangible redundancy built into the system that trades off cost-efficiency $\left(\mathrm{EC}_{1} / \mathrm{EC}_{2}\right)$ for supply sufficiency and speed (SR), while the alternative option of Postponed Procurement, if combined with other options such as Multiple and Local Supplies, can lead to higher NSV. This exercise also demonstrated that the operational choices along HSCs are interrelated and some decisions made upstream can become constraints to, or are necessary prerequisites for, downstream options (e.g., Location of Supply Source, Location of Inventory, and Mode of Transport are all interrelated options). Therefore, a systematic, rather than symptomatic, approach is necessary to enable the integration of sustainability considerations into the structural design of HSCs.

Regarding the evaluation method, it could be argued that such an approach is rather crude, and this might indeed be the case. However, for the lack of a more sophisticated yet still reasonably holistic approach, this is a still a necessary first step in operationalizing sustainability in the design of HSCs. It decomposes the end-to-end processes, identifies the key operational options, assesses their sustainability implications on different dimensions, exposes sub-optimal choices, and surfaces high leveraging areas along the HSCs. The purpose of the analysis is not to reach precision, but rather to ensure relevance through identifying key sustainability leveraging points and allowing for the emergence of optimal supply chain configurations.

\subsection{Sustainability Value Flow and Emerging Sustainable Tactics}

Following the concept of "the path of least resistance", "the path of highest value" is mapped to identify the sustainable HSC configurations. This is the mapping process: 1) the values of "1", “-1", and "0" are assigned to the signs of "+", “-”, and "=”, respectively; 2) the assigned values on the three sustainability dimensions are then summarized for each operational option (e.g., Local gets the value of " 3 " and Global "-3" in P1.1); 3) the relative NSV impact value of the outperformed option in each pair is 
calculated (e.g., "6" for P1.1_Local), following the conception proposed in Section 4.1 that “unsustainability reduced (is) sustainability gained". Following such a process for each pair of operational choices, the sustainable HSC configuration plan is identified and summarized in the first column in Table $\underline{2}$.

\begin{tabular}{lll}
\multicolumn{1}{c}{$\begin{array}{c}\text { SUPPLY CHAIN } \\
\text { CONFIGURATION }\end{array}$} & EMERGENT TACTIC & $\begin{array}{c}\text { RELATIVE NSV } \\
\text { IMPACT }\end{array}$ \\
\hline PROCURE & & 6 \\
P1.1_Local Supply Source & Localization & 4 \\
P1.2_Multiple Supply Sources & Collaboration & 2 \\
P1.3_Green Products & Dematerialization & 2 \\
P1.4_Postponed Procurement & Dematerialization & 2 \\
\hline PREPARE & & 2 \\
P2.1_Low Level of Inventory & Dematerialization & 2 \\
P2.2_Vendor-Managed Inventory & Collaboration & 6 \\
P2.3_Low Level of Processing & Dematerialization & 2 \\
P2.4_Local Location of Inventory & Localization & \\
\hline DELIVER & & \\
D3.1_Land/Ocean Transport & Dematerialization & \\
\hline
\end{tabular}

Table 2 Sustainable Humanitarian Supply Chain Configuration Plan

Also shown in Table 2 are the emergent sustainable tactics. Compared with strategy, which is " $a$ pattern in a stream of decisions" (Mintzberg, 1978), tactics are the "specific actions used when applying those strategic choices" (www.web-strategist.com). These definitions differ from those in commercial supply chains that distinguish strategic, tactical, and operational decisions primarily on the time horizons of their effects (e.g., "the strategic level deals with decisions that have a long-lasting effect... include decisions regarding the number, location and capacities of warehouses and manufacturing plants, or the flow of material through the logistics network"'(Simchi-Levi et al., 2004)). HSCs need different definitions for strategic and tactic decisions since compared with commercial supply chains, they operate with a different clock speed and do not involve decisions on manufacturing plants or production technologies.

The operational choice of Local Supply Source indicates the tactic of localization. Multiple Supply Sources, including multiple suppliers from the private sector and partnerships with members in civil society for alternative sources, requires a collaboration tactic. Green Products indicates the dematerialization tactic through reducing consumption of highly polluting or short lifespan products. Postponed Procurement also 
belongs to the dematerialization tactic since it delays the deployment of physical resources until they are needed. Low Level of Inventory and Low Level of Processing lead to dematerialization, so does the Land/Ocean Mode of Transport. Vendor-Managed Inventory requires collaboration, and Local Location of Inventory, be it close to origin of supply or destination of demand, again indicates the tactic of localization.

The inductive inference surfaces three emergent sustainable tactics: localization, collaboration, and dematerialization. Among the trio, collaboration can be considered a means for localization and dematerialization, dematerialization an end (for reduction in $\mathrm{EC}_{1}$ and $\mathrm{EC}_{2}$ ), and localization both a means (for dematerialization) and an end (for SR improvement).

A summary of the relative NSV impact value for each tactic shows that localization has the highest value (12), dematerialization the second (10), and collaboration the least (6). For the two occasions that the localization tactic appears within the nine operational elements (P1.1 and P2.4), it gets the highest value as a single operational decision each time (6). This implies that localization is likely to be a high leveraging tactic that can simultaneously benefit all three sustainability dimensions. Validation of this can be found in the evidence that the value of localization has been increasingly recognized by both academics and practitioners (Kretschmer et al., 2014, Haavisto and Kovács, 2019).

On the other hand, the dematerialization tactic appears on five occasions, but gets the lowest value as a single operational decision each time (2) because it almost always trades off SR for reduction in EC 2 . This can probably explain why the environmental dimension is often ignored in both humanitarian practices and research - it is not an easy decision to dematerialize since it might compromise the service quality of the humanitarian missions. It was argued previously about the necessity for "prioritization" between $\mathrm{EC}^{2}$ and SR. Such prioritization, preferably with a well-developed context-contingent weighting scheme, is only feasible when there is a systematic methodology to guide the decision-making process and the supply chain system is robust and reliable. Otherwise, it would always be a less risky and more appealing choice to fall back to the "a-map-a-sap" operation mode.

The above sustainability value mapping method is rather simplistic, and the quantification of comparative sustainability impacts of alternative options is only directional, so the resultant numbers are 
not supposed to be taken at face value. However, as previously argued, we believe that breadth is more valuable than precision at this early stage of sustainable HSC research. Through this systematic process, the once abstract concept of sustainability becomes concrete practical decisions grounded in HSCs, and these operational choices then converge to form patterns of emergent sustainable tactics.

\section{Sustainable Humanitarian Supply Chain Strategies}

This sub-section formulates and articulates the sustainable HSC strategies by synthesizing findings from previous analyses. The findings in previous sections are first reviewed and consolidated, then a sustainable HSC framework is presented, and finally the strategic choices in specific contexts are explicated and elaborated following the Context-Intervention-Mechanism-Outcome logic (Denyer et al., 2008).

As shown in the research framework (Figure 1), this paper started by examining the sustainability implications of the dynamics between supply and demand at different stages of the lifecycle of disaster responses (Figure 2). The analysis found that the CSFs in HSCs, supply speed and supply sufficiency, are determined by urgency and unpredictability $\left(\mathrm{U}^{2}\right)$ in the operating contexts. A $2 \times 2$ context-contingent SCC matrix was then proposed to address the contextual contingencies and the CSFs (Figure 3).

The concept of sustainability was then examined in Section 4 and the single bottom line of NSV in humanitarian operations was proposed (Figure 5). The associations among the three sustainability dimensions were analyzed, the NSV impacts of $\mathrm{U}^{2}$ and SCC examined, and a qualitative formula of NSV was postulated $\left(N S V=f\left(U^{2}, S C C,\left(S R, E C_{1}, E C_{2}\right)\right)\right)$.

Next, the structural components of HSC were depicted using a generic supply chain framework (Figure 6). These HSC components were then decomposed into operational elements with alternative operational options assessed for their performance impacts on the three sustainability dimensions (Table 1). After that, "the path of highest value" was mapped and the sustainable HSC structural configurations identified (Table 2). This evaluation process surfaced three prominent sustainable HSC tactics: localization, dematerialization, and collaboration. All these findings synthesize and converge into a coherent sustainable HSC framework, illustrated in Figure 7: 


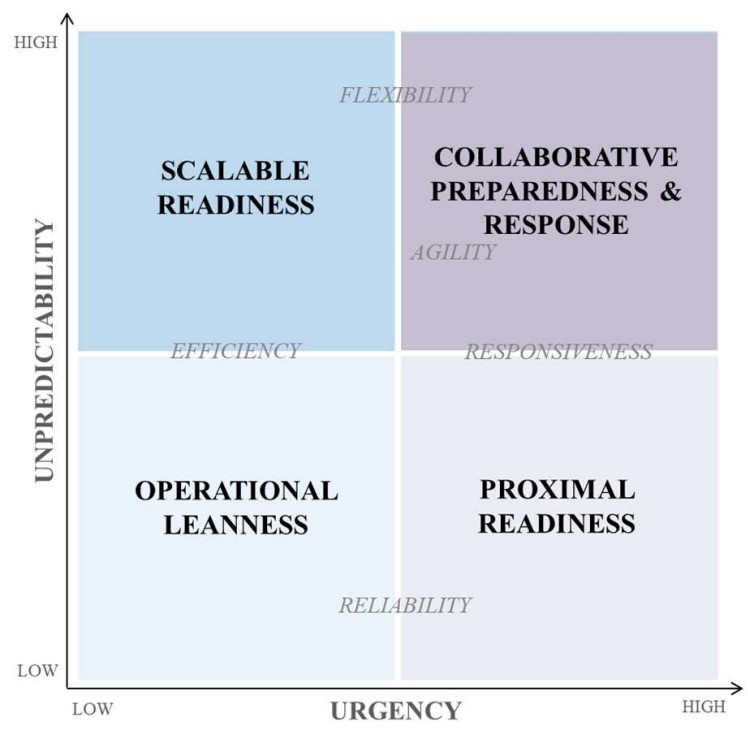

Figure 7 Sustainable Humanitarian Supply Chain Framework

The framework is a synthesis of the $2 \times 2$ SCC matrix and the emergent sustainable HSC tactics. The SCC matrix developed through deductive reasoning identifies what capabilities are needed in which specific contexts in order to achieve sustainability goals. As an organization needs to develop the required capabilities upon its chosen strategies in order to perform well, the context-contingent SCC can be imagined as an already "revealed" upper layer on top of the layer of sustainable HSC strategies that is yet to be revealed. On the other hand, the emergent sustainable tactics identified through inductive reasoning are the specific actions that can be used when applying the chosen strategies - they can be imagined as another "revealed" layer underneath the "latent" layer of sustainable HSC strategies. By putting together the capability layer and the sustainable tactics layer, the strategy layer can be readily inferred, as shown in

\section{Figure 7.}

\section{- Operational Leanness}

In low urgency/low unpredictability contexts $\left(\mathrm{UG}_{\mathrm{L}} / \mathrm{UP}_{\mathrm{L}}\right)$, Operational Leanness should be the strategic focus for NSV. Such situations do not require high speed of response and the forecasting for demand is relatively reliable for supply planning. Therefore, dematerialization should be the priority, and efficiency improvement practices (such as process standardization and utilization optimization) can be 
implemented for cost reduction without necessarily compromising SR. This is the area where operational research $(\mathrm{OR})$ techniques can make the most contribution given their strength in optimizing utilization from constrained resources (Besiou and Van Wassenhove, 2020).

\section{- Scalable Readiness}

In low urgency/high unpredictability contexts $\left(\mathrm{UG}_{\mathrm{L}} / \mathrm{UP}_{\mathrm{H}}\right)$, Scalable Readiness should be the strategic focus for sustainability. The focus should be shifted to the collaboration tactic for scalable sufficiency, postponement of physical resource deployment, and ultimately, dematerialization. Collaboration in $\mathrm{UG}_{\mathrm{L}} / \mathrm{UP}_{\mathrm{H}}$ situations includes such practices as inventory pooling and resource sharing among agencies and NGOs (a common resource pool), partnership with the private sector, and collaboration with media and civil society for in-kind donation elicitation.

\section{- Proximal Readiness}

In high urgency/low unpredictability contexts $\left(\mathrm{UG}_{\mathrm{H}} / \mathrm{UP}_{\mathrm{L}}\right)$, the sustainable supply chain strategy is Proximal Readiness. The strategic priority should be on localization for proximity of readiness. Localization practices include prepositioning of vendor-managed stocks close to disaster venues, and capability building for local partners in preparation for readiness of response.

\section{- Collaborative Preparedness \& Response}

The high urgency/high unpredictability contexts $\left(\mathrm{UG}_{\mathrm{H}} / \mathrm{UP}_{\mathrm{H}}\right)$ are the most challenging and require more sophisticated supply chain strategies. The proposed strategy for such situations is Collaborative Preparedness \& Response (CPR). The focus of the CPR strategy is to develop a global virtual common resource pool ready for emergency response. The aim is to develop preparedness at a global scale ready for local responses. A virtual supply network, with global coverage committed for ready deployment in local responses, needs the deployment of all three sustainable tactics of collaboration, localization, and dematerialization. It requires close collaboration through partnership with the private sector and civil society in order to ensure proximity and speed through scale of coverage. 
The CPR strategy substitutes prepared intangible redundancy (committed virtual supply) for prepositioned tangible redundancy (safety stocks) to hedge against the risks of forecast errors and the high costs of early physical material deployment. Figure 8 illustrates the idea that a committed virtual supply pool suffices to cover highly fluctuating and unpredictable demands of disaster response missions and the relatively stable demand of development missions. With scale of such committed supply base and global coverage, it may reach proximity to demand points and ensure both sufficiency and speed of disaster responses. Therefore, although the CPR strategy demands the most sophisticated supply chain capability portfolio, its positive sustainability impacts surpass all three other strategies.

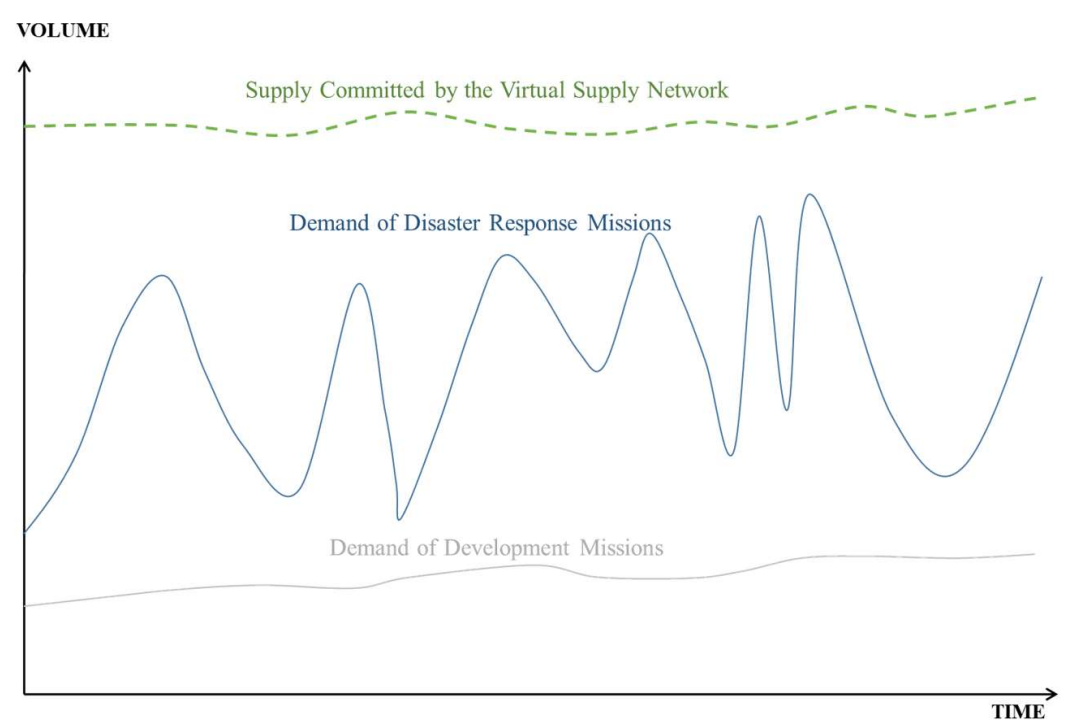

Figure 8 Supply and Demand Patterns with the CPR Strategy

\section{- Design Propositions}

To sum up, we follow the basic pragmatic logic (Van Aken et al., 2016) and propose the following sustainable HSC strategies: I) Operational Leanness in low urgency/low unpredictability contexts; II) Scalable Readiness strategy in low urgency/high unpredictability contexts; III) Proximal Readiness in high urgency/low unpredictability contexts; IV) Collaborative Preparedness \& Response in high urgency/high unpredictability contexts. Furthermore, as the context-contingent sustainable supply chain strategies (SCS) have been formulated, the formula of NSV needs to be modified accordingly and finalized as follows: 


$$
N S V=f\left(U^{2}, S C S,\left(S R, E C_{1}, E C_{2}\right)\right) .
$$

The proposed design propositions on sustainable HSC strategies are summarized in Table 3 following the Context-Intervention-Mechanism-Outcome (CIMO) logic:

(C) Contexts SC Strategies

\begin{tabular}{|c|c|c|c|}
\hline $\mathrm{UG}_{\mathrm{L}} / \mathrm{UP}_{\mathrm{L}}$ & $\begin{array}{l}\text { Operational } \\
\text { Leanness }\end{array}$ & $\begin{array}{l}\text { - Optimization of utilization } \\
\text { - Standardization of processes } \\
\text { - Scale of operations }\end{array}$ & $\begin{array}{l}\text { Cost-efficiency, } \\
\text { dematerialization }\end{array}$ \\
\hline $\mathrm{UG}_{\mathrm{L}} / \mathrm{UP}_{\mathrm{H}}$ & $\begin{array}{l}\text { Scalable } \\
\text { Readiness }\end{array}$ & $\begin{array}{l}\text { - Resource pooling/sharing with other } \\
\text { agencies/NGOs } \\
\text { - Collaboration with civil society for in- } \\
\text { kind donation elicitation } \\
\text { - Postponement of physical resource } \\
\text { deployment }\end{array}$ & $\begin{array}{l}\text { Cost-efficiency, } \\
\text { flexible sufficiency, } \\
\text { dematerialization }\end{array}$ \\
\hline $\mathrm{UG}_{\mathrm{H}} / \mathrm{UP}_{\mathrm{L}}$ & $\begin{array}{l}\text { Proximal } \\
\text { Readiness }\end{array}$ & $\begin{array}{l}\text { - Buy time with proximity } \\
\text { - Prepositioning of vendor-managed } \\
\text { stocks at strategic locations } \\
\text { - Capability building of local partners for } \\
\text { proximal readiness }\end{array}$ & $\begin{array}{l}\text { Responsiveness, } \\
\text { collaboration, local } \\
\text { capacity building, } \\
\text { dematerialization }\end{array}$ \\
\hline $\mathrm{UG}_{\mathrm{H}} / \mathrm{UP}_{\mathrm{H}}$ & $\begin{array}{l}\text { Collaborative } \\
\text { Preparedness } \\
\& \text { Response }\end{array}$ & $\begin{array}{l}\text { - Global virtual common resource pool } \\
\text { ready for local response } \\
\text { - Proximity and speed from scale of } \\
\text { coverage } \\
\text { - Substitutes prepared capabilities for } \\
\text { prepositioned inventories }\end{array}$ & $\begin{array}{l}\text { Responsiveness, } \\
\text { large scale } \\
\text { collaboration, local } \\
\text { capacity building, } \\
\text { dematerialization }\end{array}$ \\
\hline
\end{tabular}

Table 3 Sustainable Humanitarian Supply Chain Strategies Elaborated on the CIMO Logic the operating contexts are not discrete but continuous. Therefore, the choices of SCS should not be distinctive, but rather as different levels of strategic focus attuned to their contexts (so a coordinate system instead of a $2 \times 2$ matrix is used to illustrate the framework). Also, since that many HOs have a "service mix" of dual missions and the operating contexts in disaster responses are highly dynamic, it is necessary for HOs to develop a robust portfolio of capabilities in order to fluidly execute different strategies contingent on the contexts (therefore the dotted lines instead of solid lines separating different strategic focuses).

Several assumptions have been made in the design of the sustainable HSC framework. First, it has been assumed that strategic supply chain planning and implementation are centralized in the organization, 
which may or may not be true with all HOs. For decentralized organizations, the applicability of the proposed sustainable HSC strategy framework will be limited. Second, it has also been assumed that there are no political interventions or cultural influences in developing such collaborative initiatives (these are all valid concerns in humanitarian operations, but out of the scope of this study). The third assumption is that the organization's supply chain infrastructure (such as physical assets and organizational vision and policies) are conducive to sustainable supply chain structural configurations. These assumptions might not all be realistic in practice, but they are necessary to isolate the most relevant aspects to sustainable HSC design for a focused analysis and discussion. Therefore, despite these assumptions, the proposed strategic sustainable HSC framework is still relevant and pragmatically valid given the thorough and rigorous analyses throughout this study.

\section{Conclusions and Future Research}

This paper makes three contributions to SDG research. First, it increases clarity of the concept of sustainability in the humanitarian context. It does this through proposing and postulating the concept and formula of NSV, i.e., $N S V=f\left(U^{2}, S C S\right.$, $\left.\left(S R, E C_{1}, E C_{2}\right)\right)$, as the single bottom line in sustainable humanitarian operations.

Second, it increases the operationality of SDGs in humanitarian operations. It achieves this through the design of a sustainable HSC strategy framework. The framework is developed through decomposing supply chain components into interconnected operational elements, evaluating the sustainability implications of alternative operational choices, and identifying supply chain structural configurations and sustainable tactics. This practice-based management engineering approach avoids abstract concepts and latent variables, making the design highly operational and nearly readily implementable.

Third, this study contributes to the interdisciplinarity of SDG research. It achieves this through integrating studies in humanitarian operations and SDGs through supply chain management. The subject of sustainability has been studied for decades in different fields, but these research streams tend to be fragmented and isolated from one another. Complex issues relevant to sustainability can benefit from 
insights from other disciplines and a deeper understanding of this subject requires an appreciation of all of them. Supply chain management is a logical anchoring point for the multidisciplinary conversation regarding sustainability: 1) first, it offers a holistic structure to integrate different research streams into one coherent system grounded in practice-based operations; 2) second, it enables multi-level analysis and synthesis horizontally along the supply chain and vertically across organizational hierarchies; and 3) third, it provides a standardized common language for cross-sectoral communication since almost all types of organizational activities managing flows of goods and services can be decomposed and described using a generic supply chain framework (Chen et al., 2019). These characteristics make supply chain management an ideal anchoring point for multidisciplinary communication, transdisciplinary learning, and interdisciplinary enrichment in sustainability research.

Regarding future research, there are two fruitful directions. The first is to further develop the supply chain structural configurations into a standardized sustainability performance measurement framework. Performance measurement is a critical piece of foundational groundwork on sustainability that can either significantly facilitate or hinder, lack thereof, the progress of SDG research. Progress has been made in such areas as social investing, ecological economics, and product engineering. But there does not currently exist an interdisciplinary framework to consolidate the knowledge. Future research needs to identify and integrate these currently fragmented findings into a theoretically coherent and managerially relatable generic framework. In this regard, the preliminary supply chain structural configuration can serve as a starting point. Breadth should be prioritized over depth and generality over specificity at the early stage of such study in order to ensure interdisciplinarity. It is also necessary to first adopt "divergent thinking" and then move towards "convergent action" to counter the abstract nature of sustainability, and ensure its practical relevance and operationality.

The second direction for future research is to field test the recommended sustainable HSC strategies. This study guided by the design science approach is built on intensive field experiences. However, focused field testing of the recommendations would be beneficial to evaluate their implementation feasibility and improve their operationality. Given the practical challenges in implementing these strategies in full scale, 
partial testing of a small scope would be more realistic and still desirable. A good starting point would be to pilot the Scalable Readiness strategy, since it builds the foundation for the CPR strategy without the demand for speed from high urgency. The next step would be to pilot the Proximal Readiness strategy with a limited scope to test its time-constrained operationality. In addition, focus group discussions would also be beneficial to obtain practitioner feedback regarding the challenges associated with the recommended strategies. An add-on of the field testing that belongs to the Behavioral Frontier, relevant but not discussed in-length in this study, is to elicit and explicate practitioners' mental decision models in times of emergency through scenario-based experiments. The findings can help design HSCs that make sustainable options default choices rather than relying much on practitioners' cognitive capacity and value judgement in complex and dynamic emergency responses.

With so many daunting challenges ahead, sustainability may seem like an unattainable goal. But to (mis)quote Lennon, "A dream we dream alone is only a dream. A dream we dream together is reality." 


\section{References}

ACIMOVIC, J. \& GOENTZEL, J. 2016. Models and metrics to assess humanitarian response capacity. Journal of Operations Management, 45, 11-29.

BALCIK, B. \& BEAMON, B. M. 2008. Facility location in humanitarian relief. International Journal of Logistics, $11,101-121$.

BARNEY, J. 1991. Firm resources and sustained competitive advantage. Journal of Management, 17, 99-120.

BESIOU, M., PEDRAZA-MARTINEZ, A. J. \& VAN WASSENHOVE, L. N. 2014. Vehicle supply chains in humanitarian operations: Decentralization, operational mix, and earmarked funding. Production and Operations Management, 23, 1950-1965.

BESIOU, M. \& VAN WASSENHOVE, L. N. 2020. Humanitarian operations: A world of opportunity for relevant and impactful research. Manufacturing \& Service Operations Management, 22, 135-145.

BOYNTON, A. C. \& ZMUD, R. W. 1984. An assessment of critical success factors. Sloan Management Review, 25, 17-27.

CHEN, H., DAUGHERTY, P. J. \& LANDRY, T. D. 2009. Supply chain process integration: A theoretical framework. Journal of Business Logistics, 30, 27-46.

CHEN, H. S., LAI, K.-H. \& CHENG, T. 2019. Sustainable service supply chains. In: SARKIS, J. (ed.) Handbook on the Sustainable Supply Chain. Cheltenham, United Kingdom: Edward Elgar Publishing.

CHRISTOPHER, M. \& TOWILL, D. 2001. An integrated model for the design of agile supply chains. International Journal of Physical Distribution \& Logistics Management, 31, 235-246.

CLIMATE CHANGE SERVICE, C. 2019. Record-breaking temperatures for July [Online]. Available: https://climate.copernicus.eu/ [Accessed 24 July 2019].

CORBETT, C. J. \& VAN WASSENHOVE, L. N. 1993. The natural drift: What happened to operations research? Operations Research, 41, 625-640.

DENYER, D., TRANFIELD, D. \& VAN AKEN, J. E. 2008. Developing design propositions through research synthesis. Organization Studies, 29, 393-413.

ELKINGTON, J. 1994. Towards the sustainable corporation: Win-win-win business strategies for sustainable development. California Management Review, 36, 90.

FERDOWS, K. \& DE MEYER, A. 1990. Lasting improvements in manufacturing performance: in search of a new theory. Journal of Operations Management, 9, 168-184.

FISHER, M. L. 1997. What is the right supply chain for your product? Harvard Business Review, 75, 105-117.

GRALLA, E., GOENTZEL, J. \& FINE, C. 2014. Assessing trade-offs among multiple objectives for humanitarian aid delivery using expert preferences. Production and Operations Management, 23, 978-989.

HAAVISTO, I. \& KOVÁCS, G. 2014. Perspectives on sustainability in humanitarian supply chains. Disaster Prevention and Management, 23, 610-631.

HAAVISTO, I. \& KOVÁCS, G. 2019. Sustainability in humanitarian supply chains. Handbook on the Sustainable Supply Chain. Cheltenham, United Kingdom: Edward Elgar Publishing.

HAYES, R. H. \& PISANO, G. P. 1996. Manufacturing strategy: at the intersection of two paradigm shifts. Production and Operations Management, 5, 25-41.

HELP LOGISTICS, A., KUEHNE LOGISTICS UNIVERSITY, IFRC \& ICRC 2018. Supply Chain Expenditure and Preparedness Investment Opportunities.

HOLGUÍN-VERAS, J., JALLER, M., VAN WASSENHOVE, L. N., PÉREZ, N. \& WACHTENDORF, T. 2012. Material convergence: Important and understudied disaster phenomenon. Natural Hazards Review, 15, 1-12.

HOLGUÍN-VERAS, J., PÉREZ, N., JALLER, M., VAN WASSENHOVE, L. N. \& AROS-VERA, F. 2013. On the appropriate objective function for post-disaster humanitarian logistics models. Journal of Operations Management, 31, 262-280.

HOLMSTRÖM, J., KETOKIVI, M. \& HAMERI, A. P. 2009. Bridging practice and theory: A design science approach. Decision Sciences, 40, 65-87.

HUMANITARIAN RESEARCH GROUP 2011. Greening the Humanitarian Response: 2010 Haiti Earthquake

JONSEN, A. R. 1986. Bentham in a box: technology assessment and health care allocation. Law, Medicine and Health Care, 14, 172-174.

KLEINDORFER, P. R., SINGHAL, K. \& VAN WASSENHOVE, L. N. 2005. Sustainable operations management. Production and Operations Management, 14, 482-492.

KRETSCHMER, A., SPINLER, S. \& VAN WASSENHOVE, L. N. 2014. A School Feeding Supply Chain Framework: Critical Factors for Sustainable Program Design. Production and Operations Management, 23, 990-1001. 
LEE, H. L. 2002. Aligning supply chain strategies with product uncertainties. California Management Review, 44, 105-119.

MILES, R. E. 1978. Organizational Strategy, Structure, and Process, New York City, New York, United States, McGraw-Hill.

MINTZBERG, H. 1978. Patterns in strategy formation. Management Science, 24, 934-948.

NOBLE, M. A. 1995. Manufacturing strategy: testing the cumulative model in a multiple country context. Decision Sciences, 26, 693-721.

OCHA 2018. Appeals and Response Plans 2018. New York: United Nations Office for the Coordination of Humanitarian Affairs.

PEDRAZA-MARTINEZ, A. J., STAPLETON, O. \& VAN WASSENHOVE, L. N. 2011. Field vehicle fleet management in humanitarian operations: A case-based approach. Journal of Operations Management, 29, 404-421.

PEDRAZA-MARTINEZ, A. J. \& VAN WASSENHOVE, L. N. 2016. Empirically grounded research in humanitarian operations management: The way forward. Journal of Operations Management, 45, 1-10.

RELIEFWEB. 2019. The global climate in 2015-2019 [Online]. Available: https://reliefweb.int/report/world/globalclimate-2015-2019 [Accessed 12 September 2019].

SARKIS, J. 2012. Models for compassionate operations. International Journal of Production Economics, 139, 359365.

SIMCHI-LEVI, D., KAMINSKY, P. \& SIMCHI-LEVI, E. 2004. Managing the Supply Chain: The Definitive Guide for the Business Professional, New York City, New York, United States, McGraw-Hill.

SIMCHI-LEVI, D., SCHMIDT, W. \& WEI, Y. 2014. From superstorms to factory fires: Managing unpredictable supply chain disruptions. Harvard Business Review, 92, 96-101.

SKINNER, W. 1974. The focused factory. Harvard Business Review, 114-121.

SODHI, M. S. 2016. Natural disasters, the economy and population vulnerability as a vicious cycle with exogenous hazards. Journal of Operations Management, 45, 101-113.

STAHEL, W. R. 1982. The product life factor. In: ORR, S. G. (ed.) An Inquiry Into the Nature of Sustainable Societies: The Role of the Private Sector. Houston, Texas, United States: HARC.

STARR, M. K. \& VAN WASSENHOVE, L. N. 2014. Introduction to the special issue on humanitarian operations and crisis management. Production and Operations Management, 23, 925-937.

STERMAN, J. D. 2000. Business Dynamics: Systems Thinking and Modeling for a Complex World, New York, United States, McGraw-Hill.

TOMASINI, R. \& VAN WASSENHOVE, L. 2009. Humanitarian Logistics, London, Palgrave Macmillan.

VAN AKEN, J., CHANDRASEKARAN, A. \& HALMAN, J. 2016. Conducting and publishing design science research: Inaugural essay of the design science department of the Journal of Operations Management. Journal of Operations Management, 47, 1-8.

VAN AKEN, J. E. 2004. Management research based on the paradigm of the design sciences: the quest for field-tested and grounded technological rules. Journal of Management Studies, 41, 219-246.

VAN WASSENHOVE, L. N. 2006. Humanitarian aid logistics: supply chain management in high gear. Journal of the Operational Research Society, 57, 475-489.

VAN WASSENHOVE, L. N. 2019. Sustainable innovation: Pushing the boundaries of traditional operations management. Production and Operations Management, 28, 2930-2945.

VAN WASSENHOVE, L. N. \& PEDRAZA MARTINEZ, A. J. 2012. Using OR to adapt supply chain management best practices to humanitarian logistics. International Transactions in Operational Research, 19, 307-322.

WORLD COMMISSION ON ENVIRONMENT AND DEVELOPMENT 1987. Our Common Future ("The Brundtland Report"), Oxford, Oxford University Press. 